\title{
¿Enfrentar el COVID 19 o aprender de su embate?
}

Herrera, D. ¿Enfrentar el COVID 19 o aprender de su embate? Práctica Familiar Rural. 2020 marzo; 5(1).

Diego Herrera

Univeridad UTE. Orcid: https://orcid.org/0000-0002-8400-2067

DOI: https://doi.org/10.23936/pfr.v5i1.147

Recibido: 27/03/2020 Aprobado: 28/03/2020

A medida que el brote de la enfermedad por coronavirus 2019 (COVID-19) avanza a nivel mundial, aumenta la presión sobre los investigadores, para que entreguen respuestas inmediatas tanto epidemiológicas como farmacológicas e inmunológicas. El juego mediático no permite visualizar el valor de la historia y de esta crisis como una oportunidad para promover el cambio en las políticas en salud. En otras palabras, los sistemas de salud enfrentan una acusación más o menos explícita que sentencia ¿por qué no aprendimos de las epidemias pasadas? (1), (2)

El extraordinario progreso en el desarrollo de antibióticos y vacunas durante la primera mitad del siglo XX llevó a pensar que, "ya había llegado el momento de cerrar el capítulo de las enfermedades infecciosas y declarar como ganada la guerra contra esas pestilencias". Esta frase triunfalista, atribuida a William H. Stewart, Cirujano General de los Estados Unidos en el período 1965 - 1969, solo fue una ilusión del pensamiento positivista del momento. Hace unos veinte años, el Premio Nobel de Medicina Joshua Lederberg predecía que "la guerra entre los seres humanos y los microbios continúa día a día y no está claro quién será el ganador", todas las epidemias emergentes de este siglo le dan la razón (3).

La pandemia del coronavirus SARS-Cov-2 viene marcada por su letalidad, su transmisibilidad y su impacto sanitario. Aunque la capacidad letal del COVID-19 no es extremadamente alta (alrededor del 3 por ciento) (8), es mucho mayor que la de la gripe (0,1 por ciento) y es más grave en los grupos de edad avanzada (9), personas con patologías previas y en las clases sociales, mujeres y grupos más frágiles.

Su elevada contagiosidad (existente antes de tener síntomas y persistente tras padecer la enfermedad) se extiende entre la población de forma exponencial. ¿Qué ocurre al unir ambos factores? Hace varias décadas, el epidemiólogo británico Geoffrey Rose enseñó una paradoja de la salud pública: “Una gran cantidad de personas expuestas a un pequeño riesgo puede generar muchos más casos que una pequeña cantidad expuesta a un alto riesgo" (10). Así pues, aunque el riesgo individual de morir por el COVID-19 no sea alto, el número global de muertes puede ser muy elevado (11).

El brote de SARS ocurrió a finales del 2002, no mucho después de que China retomó la soberanía sobre Hong Kong en 1997. Inicialmente se condenó al Gobierno chino por retener información y ocultar el alcance de la epidemia de SARS (5), lo cual sucedía antes de que Jiang Zemin sea presidente de China y aplicara su programa económico para extender la influencia china en el extranjero, al tiempo que reforzaba su poder en el hogar. La autoridad mejorada le ha permitido establecer medidas draconianas de contención de enfermedades infecciosas al estilo Mao, incluido el cierre de ciudades (6), con el elogió de la mayoría de países de occidente, en lo que la OMS denomina "probablemente el esfuerzo de contención de enfermedades más ambicioso y agresivo de la historia" (7). 
Las principales razones del éxito inicial de los modelos asiáticos incluyen: una intervención rápida y masiva del gobierno al haber actuado sin cuestionamiento público de ningún tipo, a disponer de la experiencia de epidemias anteriores, y a tener recursos suficientes. La experiencia de los países europeos y de Norteamérica, muestra que los recursos económicos no son suficientes, que existen luchas de poder político en los denominados equilibrios parlamentarios y que los poderes económicos juegan un papel relevante (12)

Los países occidentales independientemente del modelo político de sus estados y del sistema de salud con el que cuenten, sea neoliberal, mixto, basado en APS, con alta inversión o con muy poca inversión, han expuesto sus debilidades ante la epidemia, revisando su capacidad de compras, número de camas y personal capacitado para enfrentar la pandemia.

Aunque la mayor parte de casos se desarrollan en forma leve, el elevado número de enfermos genera muchos casos que precisan de atención, lo cual incrementa la posibilidad de colapsar los centros socio-sanitarios y crear una "medicina de la catástrofe" (13). Los pacientes se aglomeran en hospitales, los recursos escasean, se contrata personal adicional, se cancelan vacaciones, se solicitan más equipos de protección y atención, se habilitan salas especiales, se moviliza a médicos jubilados, estudiantes y recién titulados, se utilizan hospitales de campaña, se adaptan hoteles, coliseos carpas y barcos como hospitales de campaña. El cansancio hace mella en los profesionales socio-sanitarios, muchas personas caen enfermas.

Muchos servicios ya no pueden atender adecuadamente a quienes lo necesitan acercándonos a una situación temporal de falla mundial de la sanidad pública, donde aparecen dilemas éticos sobre cómo y en quién actuar, quién puede vivir o morir, democratizándose la atención pero hacia abajo, comparándose la situación del primer mundo con lo que cotidianamente vivimos en países pobres con sistemas sanitarios públicos muy débiles o casi inexistentes (14).

Aún falta tiempo para visualizar el impacto de la pandemia en los pacientes con enfermedades habituales, aquellos que perdieron el acceso a medicinas, pruebas diagnósticas, operaciones quirúrgicas y atención no urgentes, y los procedimientos no urgentes pero necesarios para mantener su calidad de vida.

Los pensadores de la salud pública repiten las viejas estrategias, apuntando al aislamiento social para el control de la epidemia, mientras tanto el virus se propaga por todo el mundo sin respetar estaciones, climas, razas, sobrepasando todas las barreras de control, buscando un desarrollo natural de la "inmunidad de rebaño" (15).

La opción de aprender y desaprender acerca del manejo de las epidemias, está limitado para la salud pública por aquello que el economista y sociólogo Thorstein Veblen, llamó "incapacidad entrenada" - "ese estado de cosas por el cual las propias habilidades pueden funcionar como ceguera" (4). Los modos de pensamiento habituales pueden disminuir nuestra capacidad para hacer conexiones laterales. Cuando el presente se ve a través del lente de los brotes de enfermedades anteriores, generalmente nos enfocamos en las similitudes y pasamos por alto importantes diferencias, en otras palabras, las analogías crean puntos ciegos. Como comentó Burke, "una forma de ver también es una forma de no ver: centrarse en el objeto A implica descuidar el objeto B" (4).

Esta imposibilidad de aprender, tiene un costo. La primera víctima del coronavirus es el pensamiento positivista y desarrollista, y sus sistemas de salud tipo "Disney", que nunca estuvieron preparados para una catástrofe. La pandemia brinda la oportunidad de dudar de todo lo que creíamos incuestionable, las teorías neoliberales y sus sistemas de salud fraccionados, en manos del mercado; pero también cuestiona los viejos enunciados de la APS y el positivismo de la prevención total. Lo mismo sucede con el currículo de formación de los médicos, la súper especialización de los recursos humanos, los roles de los diferentes actores en salud las asignaciones presupuestarias en salud, todas estas son víctimas que se suman a la mortalidad del coronavirus.

Un pequeño virus, desnuda las limitaciones conceptuales de la llamada Atención Primaria de Salud, que sin rumbo no tiene ninguna propuesta frente a la pandemia Este microorganismo se burla del pragmatismo y utilitarismo político que rige su práctica, dejando a la APS aislada, ansiosa, huérfana, ante el fracaso de la medicina hegemónica y del pensamiento lineal y positivista de la medicina (16).

\section{Referencias bibliográficas}

1. Organización Mundial de la Salud. Coronavirus disease 2019 (COVID-19) situation report-38. Feb 27, 2020. https://www.who.int/docs/defaultsource/coronaviruse/situation-reports/20200227-sitrep-38-covid19.pdf?sfvrsn=47fdaf7_4. 
2. Specter $M$. The new coronavirus and preparing for the next viral pandemic. The New Yorker, Feb 15, 2020.

https://www.newyorker.com/news/dailycomment/the-new-coronavirusand-preparing-for-the-next-viralpandemic.

3. Esparza, José. (2016). Epidemias y pandemias virales emergentes: ¿Cuál será la próxima?. Investigación Clínica, 57(3), 231-235. Recuperado en 05 de marzo de 2020, de

http://ve.scielo.org/scielo.php?script=sci_arttext\&pid=S0535-

$51332016000300001 \& \operatorname{lng}=e s \&$ tlng=en.

4. Burke K. Permanence and change: an anatomy of purpose. Berkeley, CA University of California Press, (1935) 1984.

5. Huang Y. The SARS epidemic and its aftermath in China: a political perspective. In: Learning from SARS: preparing for the next disease outbreak: workshop summary. Washington, DC: National Academies Press, 2004: 116-36

6. Zhong R, Mozur P. To tame coronavirus, Mao-style social control blankets China. The New York Times, Feb 15, 2020. https://www.nytimes. com/2020/02/15/business/china-coronavirus-lockdown.html (accessed Feb 17,2020

7. WHO. Press conference of WHO-China Joint Mission on COVID-19. Feb 24 2020. https://www.who.int/docs/default-source/coronaviruse/ transcripts/joint-mission-press-conference-script-englishfinal.pdf?sfvrsn=51c90b9e_2.

8. Pueyo, T. Coronavirus: Why You Must Act Now. Medium. 13-03-20. https://medium.com/@tomaspueyo/coronavirus-act-today-or-people-willdie-f4d3d9cd99ca.
9. Severe Outcomes Among Patients with Coronavirus Disease 2019 (COVID19) - United States, February 12-March 16, 2020. MMWR Morb Mortal Wkly Rep 2020;69:343-346. DOI:

http://dx.doi.org/10.15585/mmwr.mm6912e2external icon

10. Rose, G. The strategy of preventive medicine. New York: OUP, 1992

11. Benach, J. La pandemia, detonante y espejo de la crisis de salud pública, Pensamiento, Sociedad, El Viejo Topo, 25 marzo, 2020

12. Horton, R. "Scientists have been sounding the alarm on coronavirus for months. Why did Britain fail to act?" The Guardian, 18-03-2020. Accesible en:

https://www.theguardian.com/commentisfree/2020/mar/18/coronavirusuk-expert-advice-wrong

13. Nuria Alabao, Ernest Cañada, Ivan Murray. Una pandemia con sesgo de clase. El Salto, 17-03-2020. Accesible en: https://www.elsaltodiario.com/coronavirus/teletrabajo-pandemiadesigualdad-aislamiento-lucha-sesgo-clase

14. Gilbert M, Pullano G, Pinotti F, et al. "Preparedness and vulnerability of African countries against importations of COVID-19: a modelling study". Lancet 2020;395:871-877. Accesible en:

https://www.thelancet.com/action/showPdf?pii=S01406736\%2820\%2930411-6

15. Fox JP, Elveback L, Scott W, Gatewood L, Ackerman E. Herd immunity: basic concept and relevance to public health immunization practices. Am J Epidemiol 1971;94:179-89.

16. Herrera Ramírez D. APS: la revolución fue controlada. Práctica Familiar Rural. 2018 noviembre; 3(3). 